\title{
METHODS OF CALCULATION AND REMOTE-SENSING MEASUREMENTS FOR THE SPATIAL DISTRIBUTION OF GLACIER ANNUAL MASS BALANCES*
}

\author{
By V.G. KONOVALOV \\ (S.S.S.R. Goskomgidromet, Sredneaziatskii Regional'nyi Nauchno-Issledovatelskii Institut, \\ 700052 Tashkent, U.S.S.R.)
}

ABSTRACT. The areal distribution of glacier annual mass balance $b(z)$ is an important characteristic of the existence of glacierization and its evolution. At present the measured value of annual mass balance at different elevations is only available for a limited number of mountain glaciers of the globe, because of the great amount of labour required for such measurements.

The analysis of long-term mass-balance measurements made at Abramova glacier, Limmerngletscher, White Glacier, Hintereisferner, and Peyto Glacier has revealed that for each year the spatial distribution of annual mass balance is well described by quadratic equations. The main variable in these equations is altitude $(z)$. The various parameters of these formulae are estimated by the author for mean weighted height of the ablation and accumulation areas, and for the glaciers as a whole. It is found that the parameters of annual mass balance for each glacier can be calculated from formulae which include combinations of the following variables: annual balance at one of the three weighted altitudes, maximum annual snow-line elevation, annual and seasonal amounts of precipitation, and air temperatures at nearby meteorological stations.

Therefore, in order to calculate the distribution of annual mass balance as a function of absolute altitude, it is sufficient to obtain a value for mass balance measured only at a single point on a glacier, and common meteorological observational data. A comparison of actual and calculated values of mass balance has shown good agreement between them.

Considering the successful use of aerial remote-sensing for the measurement of snow depth in mountains by means of special stakes, it is satisfactory to accept this method for the assessment of annual mass balance at the mean weighted altitude of the ablation zone. It is possible to use aerial photo-surveys or stereophotogrammetry to resolve this problem. Then annual mass balance for the whole area of a glacier is calculated by using data from one point together with data from a nearby meteorological station.

\section{INTRODUCTION; INITIAL DATA}

The detailed and systematic measurements of mass balance $(b)$, accumulation $(A k)$, and ablation $(A b)$ that cover the whole areas of glaciers are unique information. There are only a few similar glaciers in the U.S.S.R., Switzerland, U.S.A., Austria, Canada, and Sweden.

Both the total and mean values of $A k, A b$, and $b$, applicable to the whole area of a glacier can be estimated reliably and precisely by using these data. These measurements are also used as basic information for the analysis of

*See Annals of Glaciology, Vol. 9, 1987, p. 248 for an extended abstract. a glacier's evolution and for the mathematical simulation of glacier dynamics. The long-term hydrological regime of individual glaciers and their grouping are also closely related (Konovalov, 1985) to the annual mass balance and its calculation.

In this connection, of some urgency is elaboration of the methodology for calculating $a k(z), a b(z)$, and $b(z)$ distributions based on the minimum of appropriate measurements. This problem has been considered further for a glacier's annual mass-balance distribution described analytically as a function of absolute altitude $(z)$.

To analyse and solve this problem, the long-term data from detailed measurements of annual mass balance at five glaciers have been used. Some information about these objects is given in Table $\mathbf{I}$.

\section{FORMULATION OF THE PROBLEM AND ITS GENERAL SOLUTION}

Let us state the general expressions for the total $B_{\text {t }}$ and mean $B_{\mathrm{m}}$ for glacier annual mass balances in the altitude range between the glacier's upper limit, $z_{\mathrm{u}}$, and its snout, $z_{\mathrm{s}}$ :

$$
\begin{aligned}
& B_{\mathrm{t}}=\int_{z_{\mathrm{S}}}^{z_{\mathrm{u}}} b(z) f(z) \mathrm{d} z, \\
& B_{\mathrm{m}}=F^{-1} \int_{z_{\mathrm{S}}}^{z_{\mathrm{u}}} b(z) f(z) \mathrm{d} z
\end{aligned}
$$

where

$$
F=\int_{z_{\mathrm{S}}}^{z_{\mathrm{u}}} f(z) \mathrm{d} z
$$

is the area of a glacier within the altitude range $z_{\mathrm{S}} \div z_{\mathrm{u}}$, $f(z)$ is the differential function of a glacier's area distribution, and $b(z)$ is the specific annual mass balance of a glacier at an altitude $z$.

Having applied the well-known theorem on mean product of two functions to the sub-integral expressions in Equations (1) and (2), we obtain

$$
\begin{aligned}
& B_{\mathrm{t}}=b(\tilde{z}) F, \\
& B_{\mathrm{m}}=b(\tilde{z})
\end{aligned}
$$

where $b(\widetilde{z})$ is the specific mass balance at a certain altitude $\tilde{z}$ within the range of $z_{\mathrm{s}} \div z_{\mathrm{u}}$ which provides equality between the appropriate parts of Equations (1), (4), and (2), (5).

Thus, to obtain one of the major characteristics of a glacier's regime, its annual mass balance, it is sufficient to 
TABLE I. SOME CHARACTERISTICS OF GLACIERS WHERE MEASUREMENTS OF ANNUAL MASS BALANCE ARE BEING CARRIED OUT*

\begin{tabular}{|c|c|c|c|c|c|c|c|c|c|c|}
\hline $\begin{array}{l}\text { Name of } \\
\text { glacier }\end{array}$ & Country & $\begin{array}{c}\text { Observational } \\
\text { period }\end{array}$ & $\begin{array}{c}F \\
\mathrm{~km}\end{array}$ & $z_{\mathrm{S}}$ & $\begin{array}{l}{ }^{z} \mathrm{u} \\
\quad \mathrm{km}\end{array}$ & $\begin{array}{c}\tilde{z}_{\mathbf{g}} \\
\text { above }\end{array}$ & $\begin{array}{c}\tilde{z}_{\mathrm{Ab}} \\
\text { sea-level }\end{array}$ & $\bar{z}_{\mathrm{f}}$ & $\tilde{z}_{\mathrm{Ak}}$ & References \\
\hline $\begin{array}{l}\text { Abramova } \\
\text { glacier }\end{array}$ & U.S.S.R. & $1968-83$ & 24.4 & 3.62 & 3.86 & 4.18 & 4.00 & 4.18 & 4.35 & Krenke and Suslov (1980) \\
\hline $\begin{array}{l}\text { Limmern- } \\
\text { gletscher }\end{array}$ & Switzerland & $1948-77$ & 2.39 & 2.19 & 3.42 & 2.71 & 2.50 & 2.73 & 2.86 & Kasser and others (1983) \\
\hline $\begin{array}{l}\text { Peyto } \\
\text { Glacier }\end{array}$ & Canada & $1967-74$ & 13.40 & 2.13 & 3.19 & 2.64 & 2.50 & 2.67 & 2.81 & Kasser $(1967,1973)$ \\
\hline $\begin{array}{l}\text { White } \\
\text { Glacier }\end{array}$ & Canada & $1960-75$ & 38.90 & 0.08 & 1.78 & 1.08 & 0.57 & 0.92 & 1.41 & $\begin{array}{l}\text { Kasser (1967, 1973); } \\
\text { Müller (1977) }\end{array}$ \\
\hline $\begin{array}{l}\text { Hintereis- } \\
\text { ferner }\end{array}$ & Austria & $1964-75$ & 9.01 & 2.41 & 3.71 & 2.98 & 2.71 & 2.97 & 3.18 & $\begin{array}{l}\text { Kasser }(1967,1973) \text {; } \\
\text { Müller }(1977)\end{array}$ \\
\hline
\end{tabular}

Note: $1 . F$ is the area of a glacier; $z_{\mathrm{s}}, z_{\mathrm{u}}$, and $\bar{z}_{\mathrm{f}}$ are the altitudes of a glacier's snout, upper point of a glacier, and the firn line, respectively; $\widetilde{z}_{\mathrm{g}}, \widetilde{z}_{\mathrm{Ab}}$, and $\widetilde{z}_{\mathrm{Ak}}$ are the mean altitudes weighted by areas: the glacier as a whole $(g)$, ablation $(\mathrm{Ab})$, and accumulation (Ak) spheres. 2. Annual mass balances are estimated for every $100 \mathrm{~m}$ height increment.

*Mean and mean weighted characteristics of the glaciers in Table I are defined by the author. The mass-balance data for Abramova glacier were obtained by the glaciological expedition of the Central Asian Regional Research Institute and were kindly provided to the author by its member G.M. Kamnyansky.

make the appropriate measurements only at the altitude $\widetilde{z}$. It is possible to determine the value of $\tilde{z}$ if an analytical form of the function $b(z)$ is known. So, in the linear relation $b=k_{1} z, \tilde{z}$ is a mean weighted altitude of a glacier, because

$$
\bar{z}=F^{-1} \int_{z_{\mathrm{S}}}^{z \mathrm{u}} z f(z) \mathrm{d} z
$$

or

$$
\bar{z}=\left(z_{\mathrm{u}}-z_{\mathrm{S}}\right)^{-1} \int_{z_{\mathrm{S}}}^{z_{\mathrm{u}}} z \mathrm{~d} z=0.5\left(z_{\mathrm{u}}+z_{\mathrm{S}}\right) .
$$

If $b(z)$ is a non-linear function of the form

$$
b(z)=b\left(z_{0}\right)\left[1+k_{2}\left(z-z_{0}\right)+k_{3}\left(z-z_{0}\right)^{2}\right]
$$

where $b\left(z_{0}\right)$ is the value of mass balance at some altitude point $z_{0}$ on a glacier, and $k_{2}, k_{3}$ are the empirical coefficients, then, according to Borovikova and others (1972), the mean value of mass balance for the whole glacier can be defined by the formulae:

$$
B_{\mathrm{m}}=b\left(z_{0}\right)\left[1+k_{2}\left(\bar{z}-z_{0}\right)+k_{3}\left(\bar{z}-z_{0}\right)^{2}\right]+b\left(z_{0}\right) k_{3} \sigma_{z}^{2}
$$

or

$$
B_{\mathrm{m}}=b(\bar{z})+b\left(z_{0}\right) k_{3} \sigma_{z}^{2}
$$

where $\sigma_{z}^{2}$ is the variance of a glacier's altitudes.

The next methodological conclusion is the result of previous analyses: the measurement of $b$ (specific annual mass balance) at the mean weighted altitude of a glacier ensures the determination of both the total and mean values of annual mass balance on condition that the distribution of $b(z)$ has a quasi-linear form. This conclusion, first, allows considerable simplification of quite laborious measurements of the mass-balance components and commends it as a routine practice; secondly, it is a methodological substantiation of the application of remote-sensing platforms (helicopters, aircraft, and satellites) for evaluating annual values of $A k, A b$, and $b$.

Together with measuring the integral characteristics of the regime, it is undoubtedly of fundamental and applied scientific significance to calculate the distribution of $a k(z)$, $a b(z)$, and $b(z)$ for the whole area of a glacier. It is obvious that the above-mentioned distributions could be easily computed for any year, if the empirical coefficients $k_{2}, k_{3}$ in Equation (7) are known a priori. Furthermore, we should consider how to find the values of $k_{2}, k_{3}$, if one has a long-term series of annual mass-balance measurements in the respective altitude zones of a glacier.

\section{ANNUAL MASS BALANCE AS A FUNCTION OF ALTITUDE}

The graphical analysis of the annual mass-balance distribution for different years (Fig. 1) at Abramova glacier, Limmerngletscher, Peyto Glacier, and Hintereisferner has revealed the following:

(1) Distributions of $b(z)$ for these glaciers are non-linear functions.

(2) It is possible to use linear relationships for the satisfactory approximation of $b(z)$ distribution separately in ablation and accumulation areas.

These conclusions are probably of a general character and were used to simplify the methods of definition and calculation of the integral and differential values for glacier mass balances by using a limited amount of data. In particular, from the linearity of $b(z)$ in the range of $z_{\mathrm{s}} \div$ $z_{\mathrm{f}}$ and $z_{\mathrm{f}} \div z_{\mathrm{u}}$, it follows that, to obtain mean or total values for annual mass balance in both the tongue and the 

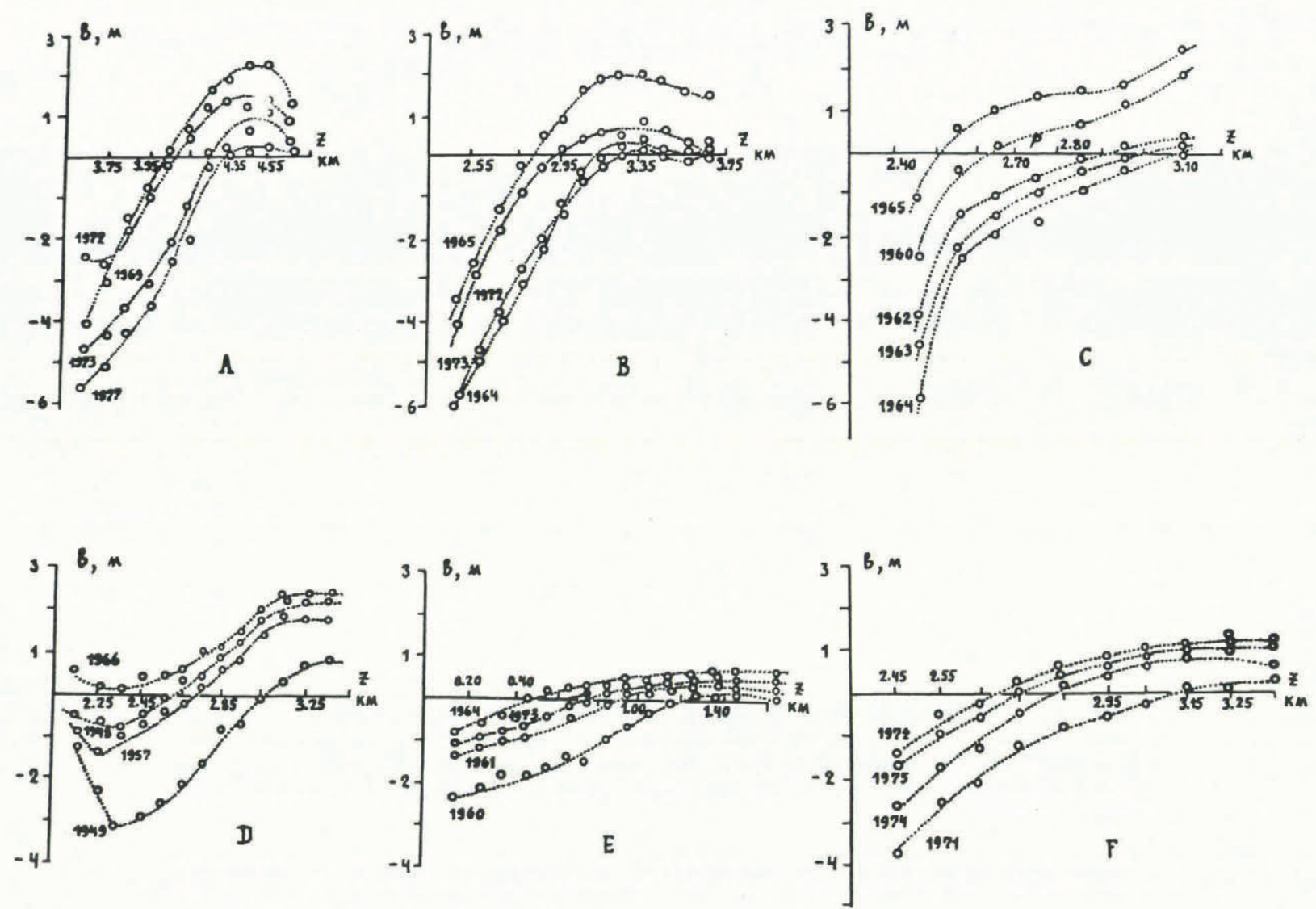

Fig. 1. Dependence of annual mass balance $(b, m)$ on absolute altitude $(z, \mathrm{~km})$ for $a$ number of glaciers. A, Abramova Glacier; B, Hintereisferner; C, Silvretta Glacier; D, Limmerngletscher; E, White Glacier; F. Gries Glacier.

nourishment areas of glaciers, it is sufficient to make measurements only at the mean weighted altitudes of those two parts of a glacier.

The analytical description of the $b(z)$ relationships for each year has been made on the basis of the long-term data for Abramova glacier, Limmerngletscher, Peyto Glacier, White Glacier, and Hintereisferner. In all cases, it was found that the second-order polynomial provided the appropriate quality for $b(z)$ approximation. Thus, for Limmerngletscher, it was defined that in the period 1948-77 the correlation ratio of the $b(z)$ relationship exceeded 0.92 in 23 cases and in five cases it was in the range of 0.80 0.90; for Hintereisferner, the correlation ratio was greater than 0.99 in all cases during 1964-75; for Abramova glacier, this ratio was only once lower than 0.97 . The same closeness of relationships was found for both Peyto and White Glaciers.

Equation (7) is the most suitable for calculation of the annual $b(z)$ distribution, because the actual data for mass balance at the altitude $z_{0}$ are used in it. The above conclusions about the form of the empirical function $b(z)$ for these glaciers serve as a basis for selecting one or several $z_{0}$ altitudes.

\section{CALCULATION OF THE $b(z)$ DISTRIBUTION AND ITS ASSESSMENT}

One of the main stages in the method for $b(z)$ calculation is the $a$ priori determination of the $k_{2}, k_{3}$ coefficients in Equation (7). This should be done by describing $k_{2}, k_{3}$ as those functions most easily determined. With this objective, and according to the recommendations of Borovikova and others (1972), the long-term series of $k_{2}, k_{3}$ coefficients was derived both for the mean weighted altitudes of ablation and accumulation areas, and for the glacier as a whole. Such coefficients were derived for all the glaciers considered here.

Then, multi-variate equations of linear regression were selected in order to calculate the $k_{2}, k_{3}$ coefficients for each glacier. A combination of arguments minimizing the root-mean-square error in the calculations was defined by using a step-wise selection procedure. The initial set of independent variables included:

(1) Annual mass balances at the mean weighted altitudes $\left(z_{0}\right)$ of ablation and accumulation areas of a glacier, and mean altitude of the firn line.

(2) Maximum altitude of the snow line.

(3) Mean air temperature for the periods OctoberSeptember, May-September, and June-August.

(4) Precipitation totals for the period June-August, and for a whole year.

(5) Annual run-off.

Examples of the working formulae for calculation of the $k_{2}, k_{3}$ coefficients and some features of these equations are given in Table II. To define $a$ priori the $k_{2}, k_{3}$ coefficients in Equation (7), it is sufficient to have data on mass balance at one point on a glacier in addition to the easily measured meteorological features (air temperature and precipitation). After $k_{2}, k_{3}$ have been determined, it is not difficult to calculate the distribution for $b(z)$ in a given year.

A qualitative estimate was made for the annual massbalance distribution calculated from Equation (7). As the points for $z_{0}$, where values of $b\left(z_{0}\right)$ were assumed to be known, $\tilde{z}_{\mathrm{Ab}}, \widetilde{z}_{\mathrm{Ak}}, \widetilde{z}_{\mathrm{g}}$, and $\bar{z}_{\mathrm{f}}$ were tested successively at the above glaciers. Figure 2 gives the histograms for the relative deviations $\Delta b(z)$ of the calculated annual mass-balance values from the measurement data in the altitude zones at Abramova glacier. Graphs for $\Delta b(z)$ distributions at the other four glaciers are of a similar character. 
TABLE II. EMPIRICAL EQUATIONS FOR THE DETERMINATION OF THE $k_{2}$ AND $k_{3}$ COEFFICIENTS USED IN THE CALCULATION OF $B(z)$ DISTRIBUTIONS BY EQUATION ${ }^{(7)}$

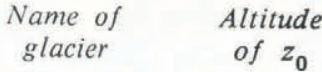

Formulae

$$
\begin{aligned}
& \bar{z}_{\mathrm{f}} \quad u k_{2}=-0.75 u b\left(\tilde{z}_{\mathrm{Ab}}\right)+0.27 u \bar{\theta}_{\mathrm{VI}-\mathrm{VIII}} \\
& k_{3}=-6.76 \times 10^{-4} b\left(\tilde{z}_{\mathrm{Ab}}\right)+5.59 \times 10^{-3} q_{\mathrm{VI}-\mathrm{VIII}}+1.48 \\
& k_{2}=-3.03 \times 10^{-4} b\left(\tilde{z}_{\mathrm{Ab}}\right)-1.72 \times 10^{-3} q_{\mathrm{VI}-\mathrm{VIII}}+2.75 \\
& k_{3}=-6.96 \times 10^{-4} b\left(\widetilde{z}_{\mathrm{Ab}}\right)+5.72 \times 10^{-3} q_{\mathrm{VI}-\mathrm{VIII}}+1.52
\end{aligned}
$$

Pe yto Glacier

$$
\begin{aligned}
\quad u k_{2} & =-0.62 u b\left(\tilde{z}_{\mathrm{Ab}}\right)-0.72 u q_{\mathrm{VI}}-\mathrm{VIII} \\
\tilde{z}_{\mathrm{Ab}} \quad k_{3} & =-8.43 \times 10^{-4} b\left(\tilde{z}_{\mathrm{Ab}}\right)+6.93 \times 10^{-3} q_{\mathrm{VI}-\mathrm{VIII}}+1.85 \\
\tilde{z}_{\mathrm{Ak}} \quad u k_{2} & =-0.70 u b\left(\tilde{z}_{\mathrm{Ab}}\right)+0.34 u \bar{\theta}_{\mathrm{VI}-\mathrm{VIII}} \\
u k_{3} & =0.82 u \bar{\theta}_{\mathrm{VI}-\mathrm{VIII}}+0.43 u q_{\mathrm{VI}-\mathrm{VIII}}
\end{aligned}
$$$$
k_{2}=-0.064 b\left(\tilde{z}_{\mathrm{Ab}}\right)+0.098 \bar{\theta}_{\mathrm{I}-\mathrm{XII}}+1.79
$$$$
\widetilde{\mathrm{z}}_{\mathrm{Ab}}
$$$$
k_{3}=-7.58 \times 10^{4} q_{\mathrm{I}-\mathrm{XII}}-0.046 \bar{\theta}_{\mathrm{I}-\mathrm{XII}}-0.094
$$$$
\tilde{\mathbf{z}}_{\mathrm{Ak}}
$$$$
k_{2}=0.11 b\left(\tilde{z}_{\mathrm{Ab}}\right)-1.08 \times 10^{-4} q_{\mathrm{I}-\mathrm{XII}}+1.36
$$$$
u k_{3}=0.85 u q_{\mathrm{I}-\mathrm{XII}}
$$

Abramova

\begin{tabular}{|c|c|c|c|c|}
\hline \multicolumn{5}{|c|}{$\begin{array}{l}\text { Argument's } \\
\text { contributions }\end{array}$} \\
\hline$x_{1}$ & $x_{2}$ & $R_{\mathrm{cb}}$ & $S_{\tilde{\mathrm{y}}} / \sigma_{\mathrm{y}}$ & $s_{\widetilde{y}}$ \\
\hline 0.76 & 0.24 & 0.95 & 0.32 & 0.08 \\
\hline 0.89 & 0.11 & 0.82 & 0.58 & 0.36 \\
\hline 0.95 & 0.05 & 0.86 & 0.52 & 0.13 \\
\hline 0.89 & 0.11 & 0.82 & 0.57 & 0.37 \\
\hline 0.42 & 0.58 & 0.85 & 0.52 & 0.15 \\
\hline 0.89 & 0.11 & 0.83 & 0.57 & 0.43 \\
\hline 0.70 & 0.30 & 0.96 & 0.30 & 0.09 \\
\hline 0.85 & 0.15 & 0.82 & 0.57 & 0.34 \\
\hline 0.37 & 0.63 & 0.71 & 0.70 & 0.08 \\
\hline 0.92 & 0.08 & 0.78 & 0.63 & 0.09 \\
\hline 0.84 & 0.16 & 0.91 & 0.41 & 0.04 \\
\hline 1.00 & - & 0.85 & 0.52 & 0.06 \\
\hline 0.75 & 0.25 & 0.86 & 0.50 & 0.05 \\
\hline 1.00 & - & 0.85 & 0.53 & 0.07 \\
\hline $\begin{array}{l}\text { blatio } \\
\text { the } \\
\text { ature } \\
\text { umme } \\
\text { com } \\
\text { mean }\end{array}$ & $\begin{array}{l}\text { and a } \\
\text { n line } \\
\text { Iring } \\
\text { orecip } \\
\text { ed co } \\
\text { uare }\end{array}$ & $\begin{array}{l}\text { ulati } \\
\tilde{z}_{\mathrm{Ab}} \text { ) } \\
\text { iumm } u \\
\text { ient } \\
\text { ient }\end{array}$ & & \\
\hline
\end{tabular}

glacier

$$
\begin{aligned}
\tilde{z}_{\mathrm{g}}=\bar{z}_{\mathrm{f}} \quad \begin{array}{l}
k_{2} \\
=
\end{array} \quad-0.09 b\left(\tilde{z}_{\mathrm{Ab}}\right)+0.04 \bar{\theta}_{\mathrm{I}-\mathrm{XII}}+1.18 \\
u k_{3}=-0.85 u q_{\mathrm{I}-\mathrm{XII}}
\end{aligned}
$$

Note: $\widetilde{z}_{\mathrm{Ab}}, \widetilde{z}_{\mathrm{Ak}}$, and $\tilde{z}_{\mathrm{g}}$ are the mean weighted altitudes respective to the ablation and accumulation areas, and to a glacier as a whole; $\bar{z}_{\mathbf{f}}$ is the mean long-term altitude of the firn line; $b\left(\widetilde{z}_{\mathrm{Ab}}\right)$ is the annual mass balance at altitude $A_{\mathrm{Ab}} ; \bar{\theta}_{\mathrm{VI}-\mathrm{VIII}}$ is the mean air temperature during the summer period; $q_{\mathrm{I}-\mathrm{XII}}$ is the annual sum of precipitation; $q_{\mathrm{VI}-\mathrm{VII}}$ is the sum of summer precipitation; $u$ is the operator for normalization of variables by G.A. Alexeev; $R_{\mathrm{cb}}$ is the combined coefficient of correlation; $S_{\tilde{y}} / \sigma_{\mathrm{y}}$ is the quality criterion of an equation; $S_{\tilde{\mathrm{y}}}$ is the root-mean-square error.
An analysis of these data allows us to reach the following conclusions, which are of methodological significance:

(1) In the majority of cases, the distribution of deviations has a symmetrical character relative to $\Delta b(z)=0$.

(2) The prevailing number of deviations does not exceed $\pm 10 \%$, indicating quite a sufficiently high quality for the $b(z)$ calculation for all the prescribed values of $b\left(z_{0}\right)$.

(3) Data on annual mass balance at the mean weighted altitude of the ablation area, and $a$ priori values of the $k_{2}$, $k_{3}$ parameters, provide sufficient information for the simple estimation of $b(z)$ at all altitude zones of a glacier.

METHOD OF REMOTE-SENSING MEASUREMENT FOR A GLACIER MASS BALANCE AND AN EXAMPLE OF ITS NUMERICAL SIMULATION

The methodological approach described above may be used to simplify and modify the estimation of $b(z)$ in all those cases when sufficiently long data series of $b(z)$ measurements are available. It is expedient to eliminate this initial condition without any loss in the quality of calculation. This is especially important for the mass-scale measurement of $b(z)$ by means of remote-sensing methods.
Let us use the quasi-linearity of the $b(z)$ distribution in the ranges of $z_{\mathrm{S}} \div z_{\mathrm{f}}$ and $z_{\mathrm{f}} \div z_{\mathrm{u}}$ (see Fig. 1). For the linear function

$$
\begin{gathered}
b(z)-b\left(z_{0}\right) / z-z_{0}=k=\text { const., } \\
b(z)=b\left(z_{0}\right)-k\left(z-z_{0}\right)
\end{gathered}
$$

where $k$ is the parameter with long-term variability. It is not difficult to define $k$ for every single year, if we rewrite Equation (10) in the form

$$
k=b\left(z_{\max }\right)-b\left(z_{0}\right) / z_{\max }-z_{0}
$$

where $z_{\text {ax }}$ is the maximum height of the snow line of a given glacier; $b\left(z_{\max }\right)=0$, according to the definition of this line; and $b\left(z_{0}\right)$ is the measured value of annual mass balance.

Any remote-sensing method is suitable for the massscale determination of $z_{\max }$ : mapping of $z_{\max }$ based on aerial and visual observations, aerial photosurveys, and satellite photography. The latter technique is the most accurate and effective. As to the $b\left(z_{0}\right)$ measurements, it gives more scope for the application of remote-sensing methods for measurements; for example, fixing from a helicopter the melted-out parts of stakes at the end of the ablation season. These stakes must be drilled into the ice at 
$z_{0}$ altitude in advance. The position of $z_{\max }$ on a glacier is also determined during the ablation period.

The simplest and easiest way is to install stakes with an appropriate vertical scale for visual reading of stake length from a helicopter flying at a low altitude. Photographing the stakes using the same camera with a telephoto lens increases the quality of such data. This method of measuring the seasonal snow-cover depth in the mountains has been used successfully in more than 33 river basins of Central Asia (Konovalov, 1977). Space photography with a high-resolution image can provide information for the determination of $b\left(z_{0}\right), z_{\max }$, and $b(z)$ on the basis of satellite data alone.

The long-term series of $b(z)$ and $z_{\text {max }}$ data for Abramova glacier and Limmerngletscher have been used to simulate the definition of $b(z)$ by remote-sensing measurements of $b\left(\tilde{z}_{\text {tu }}\right), z_{\text {max }}$, and the calculation of $k$ using Equation (12). The histograms for relative errors (see Fig. 2) show the quality of estimates determined in the usual way: $\Delta b(z)=b(z)_{\mathrm{m}}-b(z)_{\mathrm{c}} / b(z)_{\mathrm{m}}$ where $b(z)_{\mathrm{m}}$ and $b(z)_{\mathrm{c}}$ are respectively the measured and calculated values of $(b z)$.

A comparison of the three histograms in Figure 2 shows
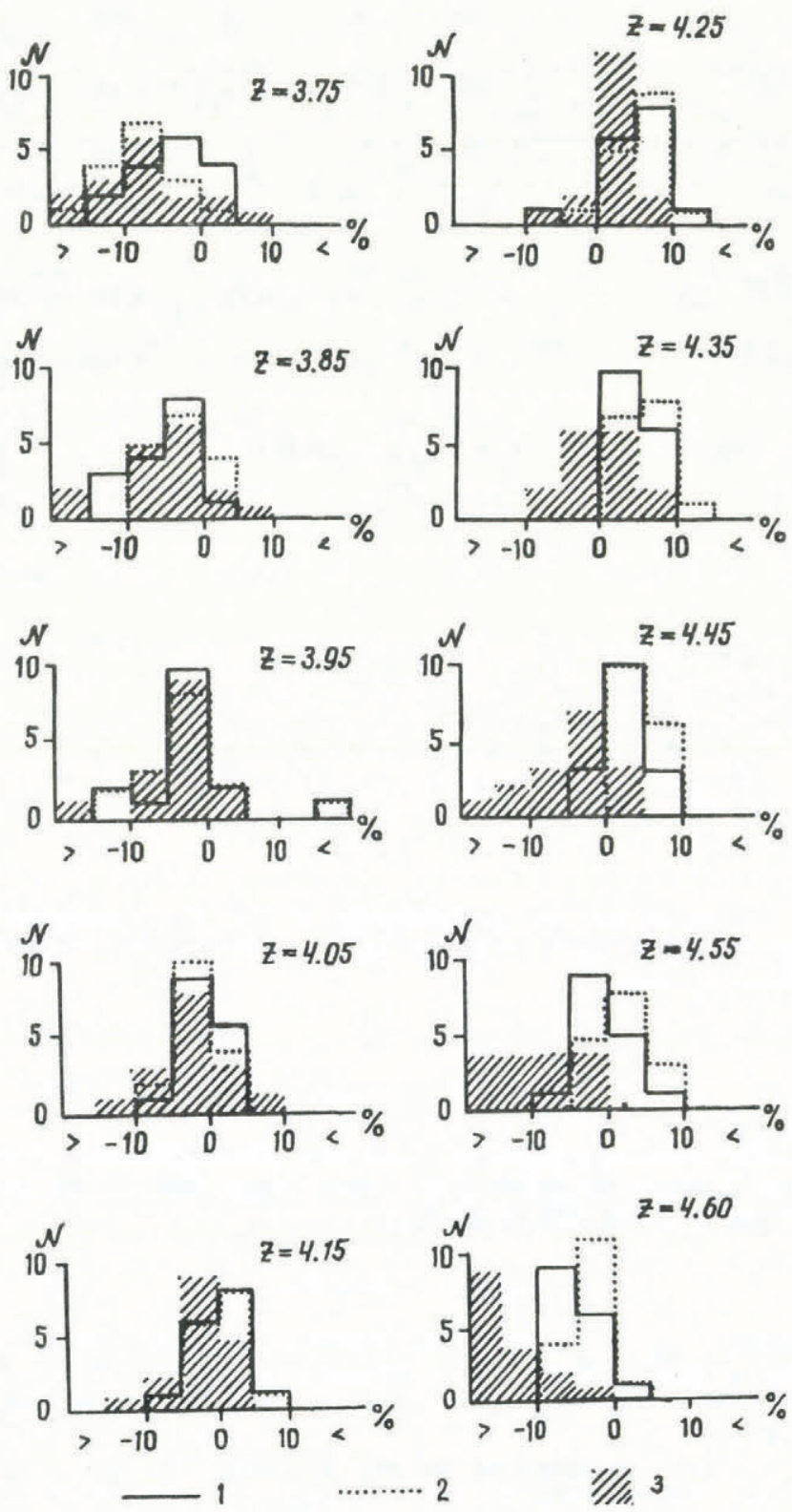

Fig. 2. Histograms for the relative errors in the calculation of $b(z)$ for Abramova glacier for the period 1968-83. Notations: 1 , based on $b\left(\widetilde{z}_{\mathrm{Ab}}\right)$ data and a priori values of the $k_{2}, k_{3}$ coefficients; 2 , the same for $\widetilde{z}_{\mathrm{Ak}}$ altitude; 3 , based on data on the numerical simulation of remote-sensing measurements of $b\left(\widetilde{z}_{\mathrm{Ab}}\right)$ and $z_{\max }$. that the $\Delta b(z)$ distributions, obtained to assess the method of remote-sensing measurement and calculation of $b(z)$, possess the same features found after an analysis of the errors.

The simulation of remote-sensing measurements of $b\left(\widetilde{z}_{\mathrm{Ab}}\right)$ and $z_{\max }$ has revealed less accuracy in $b(z)$ determinations only in the upper parts of an accumulation area. A similar conclusion was confirmed by the data for "remote-sensing measurements" of $b\left(\tilde{z}_{\mathrm{Ab}}\right)$ and $z_{\max }$ at Limmerngletscher. Therefore, a small loss in the quality of the calculations is completely compensated by simplification of the method of $b(z)$ determination based on the mass-scale remote-sensing measurements of $b\left(\tilde{z}_{\mathrm{Ab}}\right)$ and $z_{\max }$.

\section{CONCLUSIONS AND RECOMMENDATIONS}

As a result of our investigation, the following are the conclusions and recommendations.

1. For the determination of total or mean values of a glacier's annual mass balance, it is sufficient to measure specific balance at the mean weighted altitudes of the ablation and accumulation areas.

2. The one-dimensional distribution of annual mass balance is quite well described by the quadratic function in Equation (7) of altitude using $k_{2}, k_{3}$ coefficients which are defined for a $z_{0}$ point.

3. A priori calculation of $k_{2}, k_{3}$ is made by using empirical formulae, the arguments for which are standard meteorological features (air temperature and precipitation).

4. Measurement of $b\left(\tilde{z}_{\mathrm{Ab}}\right)$ or $b\left(\widetilde{z}_{\mathrm{Ak}}\right)$ and the $a$ priori determination of $k_{2}, k_{3}$ provide a sufficiently high quality for calculation of the annual mass-balance distribution according to the altitude zones of a glacier.

5. In many cases, the $b(z)$ function has a quasi-linear form for both ablation and accumulation areas of a glacier.

6. The method of calculating $b(z)$ has been expanded for wide application. Input information for this method is the remote-sensing measurements of annual mass balance at the mean weighted altitude of the ablation area and the maximum snow-line altitude $z_{\max }$.

7. The reliability of a simple method for determining $b(z)$ is confirmed by the low relative errors inherent in $b(z)$ calculations and by the histograms obtained after numerical simulation of remote-sensing measurements of $b\left(\widetilde{z}_{\mathbf{A b}}\right)$ and $z_{\max }$ for specific glaciers.

\section{REFERENCES}

Borovikova, L.N., and others. 1972. [Mathematical modelling of mountainous rivers runoff process.] By L.N. Borovikova, Yu. M. Denisov, E.B. Trofimova, and I.D. Shentsis. Leningrad, Gidrometeoizdat.

Kasser, P. 1967. Fluctuations of glaciers, 1959-1965. A contribution to the International Hydrological Decade. Paris, International Commission of Snow and Ice of the International Association of Scientific Hydrology.

Kasser, P. 1973. Fluctuations of glaciers, 1965-1970. A contribution to the International Hydrological Decade. Paris, International Commission on Snow and Ice of the International Association of Hydrological Sciences and UNESCO.

Kasser, P., and others. 1983. Les variations des glaciers suisses $1975 / 76$ et 1976/77, by P. Kasser, M. Aellen, and $H$. Siegenthaler. Zürich, Commission des Glaciers de la Société Helvétique des Sciences Naturelles.

Konovalov, V.G. 1977. Metodika i tekhnika izmereniy snezhnogo pokrova dlya gidrologicheskikh tseley. [Methods and techniques of snow cover measurements for hydrological purposes]. Materialy Glyatsiologicheskikh Issledovaniy. Khronika. Obsuzhdeniya, Vyp. 30, p. 235-55. 
Konovalov, V.G. 1985. Tayaniye $i$ stok $s$ lednikov $v$ basseynakh rek Sredney Azii. [Melting and glacial runoff in the river basins of central Asia]. Leningrad, Gidrometeoizdat.

Krenke, A.N., and Suslov, V.F., eds. 1980. [The Abramov's Glacier.] Leningrad, Gidrometeoizdat.
Müller, F. 1977. Fluctuations of glaciers, 1970-1975. A contribution to the International Hydrological Programme. Paris, International Commission on Snow and Ice of the International Association of Hydrological Sciences and UNESCO.

MS. received 15 October 1986 